\title{
Mihai Eminescu en español. Prolegómenos para un eStudio TRADUCTOLÓGICO COMPARATIVO
}

\author{
Mihal EMinescu in Spanish. Preliminaries to a \\ COMPARATIVE TRANSLATIONAL STUDY
}

\author{
Catalina Iliescu Gheorghiu \\ Universidad de Alicante \\ Alicante - Espanha \\ ORCID 0000-0002-4670-2767
}

\begin{abstract}
Resumen
Este trabajo se propone abordar la figura del poeta rumano más universal desde la proyección que ha tenido en el ámbito hispano, a través de sus exégetas y sus traductores, tanto españoles como latinoamericanos. Una vez fijadas brevemente las coordenadas de su lugar en la literatura rumana, así como en las letras universales, identificaremos algunos condicionantes que intervienen en el nivel preliminar de decisión (según el modelo Lambert-Van Gorp) del proyecto traductor, susceptibles de tener un nivel de incidencia significativo en la prevalencia de uno de los dos polos en binomios traductológicos básicos como pueden ser: aceptabilidad-adecuación; traducción filológica-traducción poética; o rasgos prosódicos-complejidad semántica. A continuación, propondremos una clasificación de estos condicionantes extraídos de la observación de cuatro versiones en lengua española de la poesía de Eminescu y analizaremos su posible influencia en el nivel preliminar de estas traducciones.
\end{abstract}

Palabras claves: Eminescu; traducción de poesía; exégesis; versiones españolas; modelo Lambert-Van Gorp.

\section{Resumo}

Este trabalho se propóe abordar a figura do poeta romeno mais universal desde a projeção que teve no âmbito hispânico, através dos seus exegetas e tradutores, tanto espanhóis como latino-americanos. Uma vez fixadas brevemente as coordenadas do seu lugar na literatura romena e universal, identificaremos alguns condicionantes que intervêm no nível preliminar de decisão (segundo

\section{Abstract}

This paper approaches the most universal Romanian poet from the viewpoint of his projection within the Hispanic context through his exegetes and translators, both in Spain and in Latin America. Once I have outlined his position within Romanian and universal literature, I will identify some of the determinants which intervene on the preliminary decision level of the trans- 
o modelo Lambert-Van Gorp) do projeto tradutor, susceptíveis de ter um nível de incidência significativo na prevalência de um dos dois polos em binômios tradutológicos básicos como por exemplo: aceitabilidade-adequação; tradução filológica-tradução poética; ou características prosódicas-complexidade semântica. Seguidamente, proporemos uma classificação destes condicionantes extraídos da observação de quatro versóes em língua espanhola da poesia de Eminescu e analisaremos a sua possível influência no nível preliminar destas traduçôes.

Palavras-chave: Eminescu; tradução de poesia; exegese; versóes espanholas; modelo Lambert-Van Gorp. lational project (according to the model introduced by Lambert and Van Gorp in modern translatology) and which are likely to intervene significantly when one of the poles prevails in such binomials, as: acceptability vs adequacy; philological vs poetic translation or prosodic features vs semantic complexity. I will also propose a classification of these determinants drawn from the observation of four Spanish versions of Eminescu's poetry and I will analyse their influence on the preliminary level of these translations.

Keywords: Eminescu; poetry translation; exegesis; Spanish versions; Lambert-Van Gorp model.

\section{Introducción}

En opinión de la ilustre comparatista ${ }^{1}$ Zoe Dumitrescu-Bușulenga (1971, p. IX), Mihai Eminescu es "el bardo nacional, el poeta que todo pueblo espera que aparezca en su historia de la cultura”, cuya obra es, según esta investigadora, quintaesencial:

Valores filosóficos, valores humanos, condición humana, condición demiúrgica, ambas conocidas y transgredidas, unidades estéticas perfectas, desnudez esencial de la palabra, consiguiendo expresar los estratos psíquicos y mentales más diversos, así es como se muestra la obra completa de la madurez eminesciana, aquella que surge de la poesía rumana para elevarse por sí misma hacia la poesía universal (DUMITRESCU-BUȘULENGA, 1971, p. XIII). ${ }^{2}$

1 Cuya obra abraza "vastas y ambiciosas dimensiones" (USCATESCU, 1989, p. 81).

2 La traducción de las citas en rumano que aparecen a lo largo de este trabajo pertenece a la autora. 
El académico de la lengua, Marius Sala (AVRAM; SALA, 2013, p. 66), muestra que entre los siglos XIV y XV, la lengua oficial de culto y de la administración en los países rumanos era el eslavonio. Sin embargo, se cree que, en este mismo período, antes de 1521 (fecha del primer texto original, no traducido sino creado en lengua rumana) se utilizaba ya el rumano en la escritura con fines privados. Después de 1560, los textos no literarios registran un crecimiento progresivo. Los escritos llamados, en un afán englobante, "literarios" (en los que predominan textos religiosos e históricos) se desarrollan entre los siglos XVII y XVIII. Un mérito especial en la fijación de la lengua rumana escrita lo tienen los eruditos del movimiento ilustrado conocido como la Escuela de Ardeal. La época moderna se subdivide generalmente en tres etapas: la premoderna (1780-1830) que trajo los primeros trabajos de normativización de la lengua, la moderna propiamente dicha (1831-1880) que fijó la diversificación estilística bajo el impulso creador de una literatura original con la generación de 1848 y la contemporánea (1881-hasta hoy), que dio lugar a la consagración de los clásicos Eminescu, Creangă, Caragiale, a finales del siglo XIX, y, a partir de ellos, a la sólida producción del periodo de florecimiento de las letras rumanas, las cuales conocen el vanguardismo, el surrealismo de principios del siglo XX, el simbolismo precursor del existencialismo y expresionismo, así como el modernismo de entreguerras, seguidos de un brutal truncamiento de la evolución literaria con la llegada del proletcultismo que propugnaba el conformismo y el falso optimismo a través de sus preceptos glorificadores del partido único y sus logros. Aun así, la década de los sesenta da lugar a una potente generación de neo-modernistas y la octava década, cerca del final de la dictadura, de una contestataria corriente postmoderna.

Aunque se le conocía entre los coetáneos por la obra ya publicada en revistas literarias, quien lo consagra es Titu Maiorescu, intelectual de espíritu humanista de amplias miras, crítico e historiador literario, mentor no solo de Eminescu, sino de toda una generación de literatos que se convierten en "clásicos", hombre de letras y también de estado, que decide confeccionar y publicar el primer volumen, llamado Poesías (1884) el cual recoge, según él mismo anuncia en el prefacio, "todos los poemas de Eminescu publicados en Convorbiri Literare (Coloquios literarios) en los últimos doce años, 
junto con algunos que solo existen en versión manuscrita, en posesión de varios particulares". La publicación se hace en ausencia del poeta, que se encontraba en Viena, reponiéndose de una crisis nerviosa, por lo que los poemas, no están revisados ni corregidos por el autor. Este gesto de su amigo y mentor se debe al hecho de que Eminescu siempre había mostrado poco apego al sino de sus obras y, a pesar de la insistencia de sus amigos, era improbable que tal iniciativa partiera de él. El volumen de Titu Maiorescu denota una selección y orden de los poemas propia de un teórico que se fija unos objetivos y sigue unas pautas, teniendo en mente al público de la época, pero también a la posteridad.

Comparado con Novalis (Die Blaue Blume), o Keats (Hyperion), pero, sobre todo, con Hölderlin en "la eterna claridad", en su Hyperion que combina titanismo y soledad, y en la calidad de ambos de rebasar el canon de la estética romántica, Eminescu fija el apogeo de la tradición literaria rumana, al igual que antes lo habían hecho Dante, Cervantes o Camoes para sus respectivas literaturas. En su obra comparatista merecedora del Premio Herder (Eminescu și romantismul German - Eminescu y el romanticismo alemán), en la que, según Uscatescu (1989, p. 81) “[...] culmina una vasta corriente exegética rumana sobre las fuentes inspiradoras del poeta nacional rumano Eminescu, formado en torno a los años 70 del siglo pasado (años de formación de Nietzche) en las universidades de Viena y Berlín, en contacto con las corrientes más importantes de la cultura alemana”, Dumitrescu-Bușulenga (1987) explica las conexiones del poeta con las Escuelas de Jena y de Heidelberg, concluyendo que el contacto con la cultura alemana no moldea, sino que "cataliza" a Eminescu quien, conoce y experimenta el ideario de los románticos alemanes, cuyos pilares eran: la unión con el folclore, la literatura medieval, la cultura mundial y el respeto por la ligazón entre palabra y sonido. Este binomio aparece también en la clasificación del universo temático que ofrece Eugen Simion (1999/2000). Este Académico de la Lengua identificaba ocho constantes de la duplicidad órfico-apolíneo o romántico-clásico que permea la obra del poeta rumano, a saber: la preocupación por la historia; el mito del nacimiento/muerte del universo; el mito del maestro como sabio y mago; el mito erótico; el onírico; el mito del regreso a los elementos primordiales; el mito 
del creador y el de la poesía (entendida como música incorporada al lenguaje). Esta última aclaración no es baladí, pues recoge el sentir de sus exégetas de que los rasgos prosódicos de esta obra quintaesencial son irrenunciables, una constante que marca las decisiones de sus traductores.

Uscătescu (1989, p. 81) remarcaba a su vez, la plena conciencia que Eminescu tenía de la función de la palabra: "[...] su poesía no es filosófica a pesar del contenido metafísico de una parte de ella, sino que es, escuetamente poética”. En pleno auge del romanticismo, opina Uscatescu (1989, p. 81), la lengua rumana vierte sus posibilidades expresivas en un auténtico poeta clásico, pero absolutamente moderno, puesto que abre la expresión y experiencia poética hacia generaciones futuras, preparando la conciencia estética para un momento plenario, como lo fue la poesía interbélica. De hecho, esta doble adscripción (propia de los titanes que subyacen en sus textos), es señalada por Manolescu (2008, p. 381) cuando lo describe como: "poeta que empuja el romanticismo hasta el modernismo, sin separarse del primero por completo, ni pertenecer en su totalidad al segundo". En la misma línea, Negoițescu (apud MANOLESCU, 2008, p. 379) a quien le debemos una de las radiografías más lúcidas y creadoras de escuela de la obra del poeta, define a Eminescu como: "romántico tardío bien templado en lo clásico".

\section{Eminescu en lengua española}

Al tratarse de un poeta-síntesis, el caso de Eminescu y su difusión en lengua española es complejo. Sin pretensiones de exhaustividad, presentaremos a continuación, algunos de los hitos de su presencia en ámbito hispano. Indudablemente, un punto de inflexión en esta trayectoria es el volumen León y Alberti (1973) precedido por una edición de 1958, publicada en Buenos Aires (Losada), es decir, desde el exilio albertiano. Avadanei (1989, p. 14) señala que en ámbito anglófono Eminescu fue conocido desde 1930 gracias a la traducción de Pankhurst y Stefanovic prologada por Bernard Shaw y seguida por numerosas otras versiones que, en su opinión, no son más que "aproximaciones" a la obra del poeta capital. Diaconu (1989b, p. 14) observa que el ámbito francófono ya podía leerlo desde la déca- 
da de los 1920, en la que apareció también la versión italiana (1927), mientras que el hispano, según lamentaba Unamuno en una carta del año 1935 hacia el romanista Iorgu Iordan, no conocía todavía a Eminescu. Es el volumen León y Alberti el que da notoriedad al poeta rumano entre los lectores de lengua espańola. Según Diaconu (1995, p. 36), se le encomienda al gran poeta español la obra más representativa de la cultura rumana debido a su interés por el país carpático y a su propia notoriedad, pues había sido traducido al rumano ya desde 1936. Al igual que Neruda, Rafael Alberti conoce Rumanía a través de festivales poéticos, respondiendo a la invitación de la Unión de Escritores, que, en los Países del Este, tras la segunda guerra mundial, llega a ser una institución clave, según Capraroiu (2008, p. 15) en el tira y afloja entre el poder político y los escritores:

La retirada de las tropas soviéticas en 1958 favorece que la Unión de Escritores plantee el aislamiento literario a nivel institucional y que ponga en marcha un proyecto de traducciones en el que participan Neruda, Alberti y María Teresa León, Hubert Juin, Luc-André Marcel y Salvatore Quasimodo, entre otros.

Los primeros poemas de Eminescu traducidos por León y Alberti aparecen, como decíamos, en la editorial Losada de Buenos Aires en 1958, gracias a un programa de traducciones de literatura rumana vía francés. En un viaje a Rumanía en 1962, llamado por el hispanista Paul Georgescu "viaje al hemisferio rojo”, la poetisa rumana Veronica Porumbacu ayuda a León y Alberti a desentrañar los significados más profundos del original y esta nueva lectura se materializaría en el volumen Poesías, publicado por Seix Barral en Barcelona en 1973. En el prólogo, los traductores hacen un recorrido imprescindible por la historia de Rumanía, desde los dacios y su rey Decébalo, conquistados por el sevillano Trajano, sin olvidar al poeta exiliado de las Tristia, por las vicisitudes del medioevo y la época moderna con sus revoluciones, para trazar el contexto en el que surge el más importante de los poetas rumanos, al que comparan con Bécquer, insistiendo en la pobreza y el amor no compartido de ambos, es decir en lo que ya había seńalado el comparatista italiano Gino Lupi partiendo del lirismo profundo y puro de ambos y del tratamiento de la naturaleza, del amor o del 
mundo legendario y nacional, según recuerda Diaconu (1989a, p. 73). León y Alberti (1973, p. 7) comparan a Eminescu "fuerte y dulce ángel de rebelión rumano" también con: Hugo, Mickiewicz, Petőfi, Esproceda o Shelley. Una vez trazada la ficha biográfica del poeta, se centran en su poesía de crítica social, de solidaridad con el pueblo, de desespero ante un orden social hacia el cual "solo encuentra críticas” (EMINESCU, 1973, p. 12). Más allá de la visión hermenéutica (que intuimos deudora de una conciencia política), León y Alberti explican su motivación en la elección del autor:

Pensamos que siempre sería mejor equivocarnos humildemente que dejar a los posibles lectores de lengua española sin conocer la poesía de Eminescu. Nos interesó al principio, pues íbamos viendo cómo su poesía hacía puente con las de los demás grandes poetas románticos del mundo y, luego, nos conmovió su actitud de noble actualidad combativa. (EMINESCU, 1973, p. 13):

Asimismo, anuncian sus textos fuente, la traducción filológica francesa y el original rumano, así como sus bazas: la ayuda de amigos y diccionarios, además de "nuestra buena voluntad en captar cuanto tan gran poeta dejó" . Los paratextos revelan que su prioridad en la labor de traslación ha sido de índole semántica más que prosódica, si bien son conscientes de "la armonía idiomática que ha asombrado a todos los críticos de Eminescu”. Optan, sin embargo, por preservar "el fuego de su aliento fuerte, casi épico, que arrastra con su alta dignidad poética", aunque se pierdan en esta "dificultosa traducción" las "sutilezas maravillosas de su música", por lo que piden literalmente perdón (EMINESCU, 1973, p. 13). Algunas de las traducciones del volumen León y Alberti de 1958, presentes en el de 1973, serían seleccionadas por Zoe Dumitrescu Bușulenga para una antología Eminescu multilingüe que se publicaría en 1971 en la editorial Albatros, donde, curiosamente, las traducciones no se anuncian como tal, sino como "[...] equivalencias eminescianas en lengua inglesa, francesa, alemana, rusa y española”.

La traductología moderna, cuyo ideario es trazado por teóricos como Toury, desplaza su foco de interés hacia el descriptivismo, con unas miras más amplias y un repertorio de preguntas sobre normas, 
roles, funciones, receptores, paratextos que indagan otras cuestiones, además del puro trasvase de formas y contenidos. Sin embargo, en los años 70, el principio reinante era todavía el de equivalencia; así es cómo se explica, que, en la contraportada del libro de 1973, se anuncie la traducción de León y Alberti en estos términos:

Tanto como el acento de rebeldía de Eminescu, su profunda indagación metafísica y su nostalgia legendaria, característica de la mejor lírica romántica, hallan en esta traducción metrificada al castellano su más adecuada equivalencia (EMINESCU, 1973).

La hispanista Dana Diaconu (1989a, p. 74-75), no comparte esta opinión, observando que la versión de León y Alberti "peca de fidelidad extrema en detrimento de la musicalidad". Si bien se consiguen soluciones muy logradas, estas parecen más cercanas a la sensibilidad poética albertiana (recordando su poesía social y comprometida) que al genio eminesciano, cuya "idea poética se empobrece" y cuya "complejidad connotativa queda anulada mediante la pérdida de la armonía sonora”. Para Diaconu (1989a), la traducción de León y Alberti desvela la falta de conocimiento de lengua rumana, así como una falta de insistencia sobre el texto origen.

En este breve repaso, cabe recordar al poeta chileno Omar Lara, cuyos lazos afectivos con Rumanía datan de los ańos 1970 cuando, tras el golpe de estado de Pinochet, recibió refugio en el país carpático, al igual que otros intelectuales de izquierdas exiliados. A la vuelta del exilio, Lara publica en Chile un volumen de Eminescu que él mismo traduce, titulado El Lucero y otros poemas con una tirada muy pequeña, que incrementa en las siguientes dos ediciones, publicadas por las editoriales "Tiempo" (1992) y "Lar" (1995). El proyecto de traducción y difusión del poeta rumano en Chile parte, no obstante, de un volumen anterior, publicado en Bucarest en la Editorial Minerva (1980) en versión bilingüe, con un prólogo de Aurel Martin y unas "Palabras-justificaciones" del propio traductor, que preceden los versos. En ellas, Lara no explica su motivación, aunque sí confiesa que desde los inicios de su labor, la antología, no dejó de suscitar, entre los poetas rumanos, la curiosidad de cómo sonaría Eminescu en espańol, algo recurrente, por otra parte, casi una obligación, dice Lara, 
[...] de averiguar hasta qué punto la obra de este rumano ya mítico en el alma de su pueblo, había calado en la conciencia y en la sensibilidad de alguien tan ajeno en el espacio, en el tiempo, en aquellas zonas tan complejas en que están imbricadas costumbres y relaciones, tradiciones, etc. (EMINESCU, 1980, p. 31).

Sobre el proceso traductor en sí, Lara no nos ofrece ningún dato, ni en torno a dificultades y soluciones adoptadas, ni en cuanto al eterno dilema contenido semántico o prosodia. En una entrevista personal, no obstante, confiesa que el volumen publicado en la editorial Minerva, trataba de conservar una forma poética que transmitiera la musicalidad del original, y que optó por una traducción con rima para cumplir las expectativas del público rumano.

No podemos obviar la aparición en la editorial "Curtea Veche" de un volumen bilingüe rumano-español en el Año Eminescu (sesquicentenario del nacimiento del poeta) con el apoyo del Ministerio de Cultura Rumano, prologado por Dumitrescu-Bușulenga. La traducción pertenece al hispanista y poeta Valeriu Georgiadi (EMINESCU, 1999, p. 14), quien traduce manteniendo, en la medida de lo posible, la métrica y la rima, o, según reza el prólogo "ha intentado, y en gran parte, ha logrado dar una exitosa equivalencia”, si bien el lector español puede que disienta. La eminescóloga rumana destaca que "la poesía es música, sonoridad misteriosa" y de ahí la importancia de "preservar la musicalidad del verso en todo su esplendor original" porque "cada idioma alza homenajes a la belleza a su manera, con sonidos específicos, difícil de reproducir, dentro de otras aglomeraciones fonemáticas" (EMINESCU, 1999, p. 11). Aunque no lo anuncie, este volumen es una reedición del publicado en 1989, en el centenario de la muerte del poeta, por el mismo traductor y con el mismo prólogo, en la editorial Minerva.

Tras el volumen León y Alberti pasarían tres décadas hasta que el público hispano tuviera de nuevo la posibilidad de encontrarse con Eminescu, esta vez, con el volumen Prínceps (2004), editado por Titu Maiorescu, el cual Dana Giurcă y José Manuel Lucía Megías traducen para Cátedra Letras Universales. Con un sólido aparato crítico en forma de un proemio firmado, desde el ámbito académico rumano, por Mircea Diaconu (2004, p. 7-13) y de una amplia intro- 
ducción (EMINESCU, 2004, p. 17-61) en la que los responsables de la edición bilingüe trazan los perfiles de la época y del autor, así como de la edición primigenia, en la que basan su propio quehacer traductor y filológico, se da paso a los poemas eminescianos en ambas lenguas, dispuestos en paralelo, no antes de ofrecer al lector una cronología bio-bibliográfica de Eminescu, así como las fuentes utilizadas para este volumen. Un nutrido apartado de apéndices abarca una serie de "comentarios de crítica genética" (EMINESCU, 2004, p. 435-459) de cada uno de los poemas que conforman el libro, y una serie de tablas (EMINESCU, 2004, p. 511-516) que contienen los datos de aparición inédita (título original, año y revista literaria) resultan de gran utilidad para el investigador. En el proemio, Mircea Diaconu recalca la vocación eminesciana de "punto de inflexión" en la cultura rumana, y "principio germinador" de grandes mutaciones en el devenir de la poesía, por desgracia poco conocido en Europa. El verso sencillo, advierte el autor del proemio, está buscado con gran esfuerzo, su claridad engańosa escondiendo una gran profundidad de pensamiento.

\section{La vigencia del modelo polisistémico Lambert-Van Gorp}

La poesía, de entre todos los géneros literarios, es la que más debate ha suscitado en torno a los conceptos tradicionales de "equivalencia" o "fidelidad", hoy día relegados, como decíamos, por la traductología moderna que, hace varias décadas dio un giro hacia el descriptivismo, dejando de preocuparse por las ecuaciones entre unidades textuales, los juicios y prejuicios heredados de una larga convivencia con el debate sobre "las bellas infieles", para ver el resultado de la traducción en su conjunto y el efecto que pretende causar en el plano de las ideas y emociones del receptor, así como el complejo proceso de toma de decisiones por parte del traductor, sometido a un sistema concéntrico de normas políticas, culturales, literarias y procedimentales.

Si el panorama de las reflexiones teóricas prescriptivas y descriptivas en torno a la traducción de poesía es controvertido, tanto más se vuelve si lo contemplamos desde el prisma de un poeta tan complejo como Mihai Eminescu. Las decisiones traductológicas se 
pueden analizar sistemáticamente con ayuda del modelo comparativo ideado por José Lambert y Hendrik Van Gorp e inspirado en la teoría de las normas (TOURY, 1976) y en la de los polisistemas (EVEN-ZOHAR, 1978). Este modelo, creado en 1985 y recogido en un volumen homenaje firmado por Delabastita, D'hulst y Meylaerts (2006), sigue vigente, según demuestran estudios como los de Lei Feng (2014) o Inggs (2003) y tiene la ventaja de ser aplicable, tanto al proceso como al producto de traducción, desde una doble perspectiva (macro y micro-estructural). Lambert y Van Gorp proponen cuatro niveles de análisis, a saber: el preliminar (título, paratextos, estrategias generales); el macro-estructural (divisiones de texto, relaciones entre tipos narrativos, estructura poética interna etc); el micro-estructural (transformaciones fónicas, gráficas, micro-sintácticas, léxico-semánticas, estilísticas etc); y el contextual-sistémico (oposiciones y relaciones entre los niveles micro y macro). Las decisiones traductológicas intervienen en los cuatro niveles (en los primeros tres de manera directa e indirecta en el cuarto). Sin embargo, dadas las características y extensión de este trabajo, no es nuestro propósito analizar aquí todos los niveles del modelo Lambert-Van Gorp, lo cual requeriría un estudio pormenorizado sobre una muestra representativa de versos que refrenden con datos las hipótesis investigadoras. Nos centraremos solamente en el nivel preliminar intentando detectar de qué manera el "factor condición" influye en las decisiones que los autores de las cuatro versiones en español de la obra poética eminesciana han tomado con respecto a su posicionamiento dentro de binomios universales como aceptabilidad - adecuación; traducción filológica-recreación poética, pero, sobre todo, en la dicotomía prioridad prosódica-prioridad semántica. Como es obvio, este posicionamiento gobierna el proyecto de traducción en su totalidad, determinando las estrategias generales y las decisiones a niveles inferiores, procedimentales. Por ejemplo, un traductor que otorga más importancia al primer término en lo que Valery llamaba "la duda entre sonido y sentido" intentará reproducir los rasgos prosódicos (métrica, rima), lo cual inevitablemente afectará al plano semántico (comprometerá significados, producirá alguna solución sintáctica antinatural o introducirá alguna lexía artificial). $\mathrm{Al}$ contrario, si el traductor elige otorgar prevalencia al contenido semántico, (tropos, connotaciones) intentará quizás mantener la mé- 
trica, aunque no la rima, (al menos no la original) o lo más probable, intentará sustituirla por una rima interna.

El factor condición y algunas de sus variables

Como hemos señalado, este factor se refiere a las características y naturaleza de la instancia traductora. Tras una observación detenida de las cuatro versiones término que constituyen el corpus de este análisis, las variables que mayor relevancia parecen adquirir con respecto a la influencia ejercida sobre las decisiones del traductor en el nivel preliminar son tres:
a) Pertenencia a la cultura origen o término;
b) Vocación (filológica, poética, traductológica);
c) Skopos (finalidad de la publicación, público receptor).

A continuación, analizaremos con el prisma de estas tres variables, una de las decisiones traductológicas preliminares más dilemáticas: la prioridad prosódica o semántica, que, en el caso de la poesía eminesciana parece preocupar constantemente a la crítica. Nuestro corpus lo conforman las cuatro versiones descritas en la primera parte de este trabajo. En el caso de Eminescu, la voz de la crítica rumana es casi unánime reclamando traducciones que respeten la musicalidad del verso original, como Dumitrescu-Bușulenga, quien insiste en la importancia de "[...] las sonoridades internas que forman la arquitectura de las cadencias armónicas", pues sus versos pueden "ser leídos como una partitura musical” (DUMITRESCU-BUȘULENGA, 1999, p. 12) y advierte en el prefacio del volumen plurilingüe (DUMITRESCU-BUSSULENGA, 1971, p. XXI) sobre el verdadero desafío del traductor: "¿Y qué hay de lo inefable de la sintaxis poética? ¿Y lo inefable de la fonética? ¡Cuán intransferibles son!”. Dos décadas después, la estudiosa seguía defendiendo la reproducción prosódica recordando la versión de León y Alberti, (DUMITRESCU-BUȘULENGA, 1999, p. 12) que, "[...] desgraciadamente, como ocurre con la mayoría de los traductores extranjeros, carece de rima”. En la misma línea, Simion (1999/2000) observa que la poesía de Eminescu es "música que toma cuerpo en el lenguaje". Creția (2012, p. 5) opina 
que la percepción de engañosa sencillez que provocan los versos de Eminescu, se debe a su magia y musicalidad. Diaconu (2004) habla del discurso eminesciano como poco figurativo, basado en eufonías, además de metáforas y campos simbólicos, en su perpetua "sed de formas perfectas". Sánchez Lizarralde (2004) también repara en su variedad de ritmo y estrofas, mientras que Caranica observa una dificultad añadida para los traductores a lenguas de tradición poética latina, pues "la prosodia de nuestra poesía rumana clásica está, en lo que concierne a los acentos que forman los yambos, los dáctilos y los troqueos, muy cerca de la prosodia alemana” (apud Uță, 2014, p. 208).

\section{a) Pertenencia a la cultura origen o término}

En el caso de nuestro corpus (que abarca las cuatro ediciones en español seleccionadas para este análisis: VT1 (León y Alberti); VT2 (Lara); VT3 (Georgiadi); VT4 (Giurcă y Lucía), nos enfrentamos a una casuística variopinta: mientras León y Alberti pertenecen ambos a la cultura término, Giurcă y Lucía forman un equipo mixto procedente de la cultura origen y meta. Por otra parte, Lara pertenece a la cultura meta, pero publica la traducción en el país origen, mientras que Georgiadi pertenece a la cultura origen y publica la traducción en el país origen, no siendo la lengua término su lengua materna, sino una lengua de estudio.

Si hacemos un repaso de la opción "sonido o sentido", en el caso de las versiones españolas recogidas aquí, vemos que León y Alberti (EMINESCU, 1973, p. 13) optan por priorizar el contenido semántico "aunque se pierdan las sutilezas maravillosas de su música”. Es una decisión meditada y así lo expresan en el prefacio. Aunque no mantienen la rima original, sus versos reconstruyen cierta cadencia, y si bien la medida del verso y el ritmo eminesciano, se reproducen pocas veces, sí se ve un esfuerzo en guardar la simetría y alternancia, entre versos largos y cortos.

El volumen de Giurcă y Lucía advierte al lector (EMINESCU, 2004, p. 63) que solo en la última fase del trabajo se han consultado anteriores traducciones que permitieron la comprensión de pasajes difíciles, indicándose las discrepancias en notas al pie. Tal 
y como afirman, su propósito fue el de ofrecer "una nueva 'versión' de los poemas de Eminescu -lo más literal posible”. Esto explica la ausencia de rima y de métrica (de hecho, el texto meta no denota un cómputo silábico, ni una distribución acentual en pos de una aproximación rítmica al verso original).

Por último, la opción de Lara (EMINESCU, 1980) y de Georgiadi (EMINESCU, 1989; 1999) de intentar reproducir los rasgos prosódicos, se debe, tal y como expresan sendos prólogos, a las expectativas del público receptor rumano. Ambos volúmenes se publicaron en Rumanía, donde la crítica, los poetas, los hispanistas y el público en general, difícilmente aceptarían una traducción que no mantuviera la rima y la métrica de la obra eminesciana original. No obstante, Diaconu (1989a, p. 74-75) opina que Lara opera cambios de significado a veces excesivos, a pesar de recuperar la rima. Conocedor de ambas lenguas, origen y meta, Lara intenta trasplantar los valores musicales (si bien a veces con rima fácil), aunque no puede evitar deformar algunas ideas, por lo que se nota un descenso en la actitud poética. Por otra parte, Georgiadi emplea a veces giros, estructuras sintácticas e incluso lexías que resultan extrañas y artificiales en su afán de restituir rima o ritmo en español.

El otro tándem representa quizás la situación ideal, en la que un traductor domina la comprensión del original y el otro, las herramientas de plasmación en la lengua meta; el resultado es poético, salvo que intervengan, como en este caso, fines específicos (traducción filológica, lo más literal posible) con su recepción más o menos entusiasta en según qué ámbito.

b) Vocación

La segunda variable nos revela también un paisaje diverso: mientras Giurcă y Lucía persiguen un fin más bien científico que estético, ofreciendo una traducción filológica (si bien Lucía es autor de poesía), León y Alberti son poetas consagrados y el resultado de su traducción es poesía. Lo mismo ocurre con Lara, quien tiene la ventaja de haberse adentrado en la obra del poeta nacional de la mano de otros poetas rumanos, viviendo la literatura de su país de acogida desde dentro y hablando su lengua. Según hemos visto, aná- 
lisis pormenorizados como el de Diaconu (1989a) muestran que es difícil tarea mantener las rimas internas y las aliteraciones (porque el rumano posee más fonemas que el español), así como la medida del verso, pues en español se extiende inevitablemente a causa del artículo proclítico y la ausencia de declinación con desinencias. Por último, Giorgiadi combina las dos facetas: es hispanista (por tanto, filólogo) y escribe poesía, lo cual parece conferirle una situación privilegiada, si no fuera porque escoge la direccionalidad poco habitual (salvo cuando intervienen fines ideológicos o paradiplomáticos, véase Iliescu Gheorghiu, 2016), traduciendo hacia su segunda lengua, en la que intenta reconstruir la prosodia. Su intención es claramente poética y estética, aunque el análisis del micronivel traductológico (que rebasa la envergadura de este trabajo), revela opciones deudoras de su condición filológica.

\section{c) Skopos}

La tercera variable se refiere al skopos o finalidad, sometida a la naturaleza del público destinatario de la traducción. En nuestro caso, salvo la versión Giurcă y Lucía, orientada hacia un lector estudioso de la vida y obra del máximo poeta rumano, al que se le ofrece, además, un aparato histórico-crítico sólido y generoso en paratextos, las otras tres traducciones se proponen una familiarización del lector con la poesía rumana, los rasgos del romanticismo de la zona, y el universo temático de la obra eminesciana, pese a que los volúmenes de Lara y Georgiadi se publiquen dentro y no fuera de las fronteras de Rumanía. Suponemos que su fin último era llegar ante un público hispano, en el caso de Lara con la reedición en Chile y en el caso de Giorgiadi, a través de los resortes de política exterior de promoción cultural del país.

En los tres volúmenes, tanto el índice de poesías incluidas como el prólogo nos revelan esta intencionalidad, si bien algunos trazos biográficos nos pueden parecer soslayados (por ejemplo, en el alegato por la voz poética oprimida en una sociedad de clases, que nos transmite el prólogo León y Alberti). El volumen de Lara es singular en su skopos: se nos presenta como un ejercicio traductor que el poeta chileno emprende ante los intelectuales rumanos con profundo cono- 
cimiento de la obra y circunstancias del poeta nacional, y al mismo tiempo, en solidaridad con el canon de la traslación prosódica para no defraudar esas expectativas. A través del paratexto titulado sintomáticamente "Palabras-Justificaciones", Lara no presenta al poeta (pues ya lo hace, en el prefacio, Aurel Martin), pero tampoco habla de los dilemas o de las decisiones y estrategias traductoras aplicadas, sino simplemente circunscribe su motivación a un marco experiencial individual. Desgraciadamente, no hemos tenido acceso a las posteriores entregas en Chile.

Por último, el volumen de Georgiadi se enmarcaría en una tradición rumana que se practicó con asiduidad durante la dictadura: la traducción inversa (de encargo) con fines propagandísticos. Es conocido el afán de los regímenes totalitarios de dar a conocer en el exterior sus logros artísticos y literarios, por lo que instituyen y financian la publicación de traducciones (seleccionadas por un órgano designado), para su distribución a través de centros culturales, embajadas o bibliotecas en el extranjero. Se trata de traducciones inversas realizadas por traductores prestigiosos, a menudo procedentes del ámbito académico. En este caso, en 1989, en el centenario de la muerte del poeta, la editorial Minerva publica la traducción de Giorgiadi. En 1999, a los diez años de la caída del régimen, y con motivo del sesquicentenario del nacimiento del poeta, el Ministerio de Cultura reedita este volumen (con homólogos en otras lenguas), probablemente como parte de una campaña de difusión más amplia. Suponemos que, aunque la versión Georgiadi se editara en Rumanía, el público rumano no era el principal destinatario, a excepción de un segmento intelectual restringido (hispanistas, poetas, universitarios) que pudieran utilizar la traducción con fines didácticos, analíticos o simplemente para verificar "cómo suena en español".

\section{A modo de conclusión}

Este trabajo pretendía ofrecer una aproximación a la obra de Mihai Eminescu (considerado por la crítica "síntesis del sentir creador del pueblo rumano y concentración de sus aspiraciones, sus vicisitudes y su devenir") a través del prisma caleidoscópico de su recepción en lengua española y desde una perspectiva diacrónica y 
transcontinental. De todos los acercamientos hispanos a su complejo universo poético, su actitud y sus circunstancias socio-históricas, hemos elegido cuatro traducciones (EMINESCU, 1973; 1980; 1999; 2004) para tratar de identificar algunas de las variables derivadas de lo que hemos llamado "el factor condición", es decir, el concerniente a las características individuales y naturaleza de la instancia traductora. Consideramos que estas variables juegan un papel esencial en la toma de decisiones de carácter general, que se producen en el nivel preliminar de la traducción (según el modelo de análisis traductológico comparativo Lambert-Van Gorp, 1985) y que influyen en los demás niveles (macro-estructural, micro-estructural y contextual-sistémico).

Tras clasificar estas variables en tres categorías, hemos procedido a verificar su incidencia en uno de los binomios más productivos y controvertidos en la diacronía de los estudios de traducción poética: la dilemática elección entre los rasgos prosódicos y la complejidad semántica, la cual, en el caso de Eminescu, cobra especial interés por al menos tres razones: 1) el aura de mito intocable que adquiere en el marco cultural rumano del siglo XX y que se refuerza durante la dictadura; 2) una larga tradición exegética rumana que considera la prosodia eminesciana irrenunciable; 3) la dificultad intrínseca de que las métricas se solapen a pesar de la similitud entre ambas lenguas y debido tal vez a ese acercamiento del verso clásico rumano a la prosodia alemana.

Por razones de extensión, nos hemos limitado a esbozar un sucinto análisis comparativo de este binomio en los cuatro textos término (VT1, VT2, VT3 y VT4) desde la perspectiva de las tres variables derivadas de la condición del traductor: a) pertenencia a la cultura origen o término; b) vocación (filológica, poética, traductológica); c) skopos (finalidad de la publicación, público receptor). Los resultados del análisis revelaron que, en efecto, la incidencia de estas variables en el nivel preliminar de decisión traductológica es significativo y confirman la viabilidad metodológica del modelo en las circunstancias dadas, es decir, contando el investigador con datos relevantes sobre los traductores y sus intenciones, recabados tanto de fuentes documentales como de los propios paratextos existentes en los volúmenes traducidos. Confiamos en que, a partir de estos prolegómenos, se puedan llevar a cabo análisis comparativos más profundos 
y transversales de los demás niveles traductológicos contemplados por el modelo Lambert - Van Gorp, que revelen muchos otros aspectos todavía ignotos sobre la obra original de Mihai Eminescu y sus traducciones.

\section{Referencias bibliográficas}

AVADANEI, Stefan. Eminescu în spațiul englez. Convorbiri literare, n. 6, 1989, p. 15-16.

AVRAM, Mioara; SALA, Marius. Les presentamos la lengua rumana. Traducción de Catalina Iliescu Gheorghiu y Delia Ionela Prodan. Alicante: Publicaciones de la Universidad de Alicante, 2013.

CAPRAROIU, Gabriela. Neruda traductor: 44 poetas rumanos (1967). Nerudiana, n. 5, 2008, p. 15-17.

CREȚIA, Petru. Cuvânt Înainte. In: . (ed.). Constelatia Luceafarului. Sonetele. Scrisorile. Bucarest: Humanitas, 2012, p. 5-7.

DELABASTITA, Dirk; D'HULST, Lieven; MEYLAERTS, Reine (eds.). Functional Approaches to Culture and Translation. Selected papers by José Lambert. Amsterdam: John Benjamins, 2006.

DIACONU, Dana. Eminescu în limbă spaniolă. Anale Științifice ale Universității Al. I. Cuza. Literatura. Iași: Editura Universității "Alexandru Ioan Cuza", 1989a, p. 73-80.

. Eminescu în spațiul iberic. Convorbiri literare, n. 6, 1989b, p. 1415.

. Traducători spanioli ai poeziei lui Eminescu. Dacia Literară, n. 19, 1995, p. 36-39.

DIACONU, Mircea. Proemio. In: GIURCĂ, Dana; MEGÍAS, José Manuel Lucía (eds.). Poesías. Madrid: Cátedra Letras Universales, 2004, p. 7-13.

DUMITRESCU-BUȘULENGA, Zoe. Cuvânt asupra ediției. In: EMINESCU, Mihai. Poezii. Poems. Poésies. Gedichte. СТИХИ. Poesías. Edición multilingüe, traducciones al español de María Teresa León y Rafael Alberti. Bucarest: Albatros, 1971.

. Eminescu și romantismul german. Bucarest: Eminescu, 1987.

. Cuvânt înainte. In: EMINESCU, Mihai. Poezii-Poesias. Reedición del volumen bilingüe de 1989. Traducción Valeriu Georgiadi. Bucarest: Curtea Veche, 1999, p. 7-10. 
EMINESCU, Mihail. Poesii. Nota sobre la edición de Titu Maiorescu. Bucarest: Editura Librăriei Socecŭ \& comp, 1884.

. Poezii. Poems. Poésies. Gedichte. СТИХИ. Poesías. Edición multilingüe. Traducciones al español de María Teresa León y Rafael Alberti. Introducción de Zoe Dumitrescu-Bușulenga. Bucarest: Albatros, 1971.

. Poesías. Traducción de María Teresa León y Rafael Alberti. Buenos Aires: Losada, 1958.

- Poesías. Traducción de María Teresa León y Rafael Alberti. Barcelona: Seix Barral, 1973.

. Poezii - Poemas. Edición bilingüe. Traducciones de Omar Lara. Prólogo de Aurel Martin. Bucarest: Minerva, 1980.

. Poezii - Poesías. Edición bilingüe. Traducciones de Valeriu Georgiadi. Prefacio de Zoe Dumitrescu-Busulenga. Bucarest: Minerva, 1989.

. Poezii - Poesías. Reedición del volumen bilingüe de 1989. Prefacio de Zoe Dumitrescu-Busulenga. Bucarest: Curtea Veche, 1999.

- Poesias. Edición bilingüe. Traducciones de Dana Giurcă y José Manuel Lucía Megías. Proemiu del académico rumano Mircea A. Diaconu. Madrid: Cátedra, 2004.

EVEN-ZOHAR, Itamar: The Position of Translated Literature Within the Literary Polysystem. In: HOLMES, James S.; LAMBERT, José; van den BROECK, Raimond (eds.). Literature and Translation: New Perspectives in Literary Studies. Lovaina: ACCO, 1978, p. 117-127.

FENG, Lei. Retranslation hypotheses revisited: A case study of twp English translations of Sanguo Yanyi - the first Chinese novel. Stellenbosch Papers in Linguistics Plus, n. 43, 2014, p. 69-86.

ILIESCU GHEORGHIU, Cătălina. Thème translation as means of propaganda. The case of romanian review. RRL, 2, LXI, Bucureşti, 2016, p. 195-206.

INGGS, Judith. Studies model to the analysis of individual dramatic texts: two case studies. Language Matters, n. 31, v. 1, 2003, p. 32-51.

LAMBERT, José; VAN GORP, Hendrik. On Describing Translations. In: HERMANS, Theo (ed.). The manipulation of literature. Studies in literary translation. Londres y Sidney: Croom Helm, 1985, p. 42-53.

MANOLESCU, Nicolae. Istoria critică a literaturii române. 5 secole de literatură. Edición Prínceps. Bucarest: Paralela 45, 2008. 
SALA, Marius; AVRAM, Mioara. Les presentamos la lengua rumana. Traducción de Catalina Iliescu Gheorghiu y Delia Ionela Prodan. Alicante: Publicaciones de la Universidad de Alicante, 2013.

SÁNCHEZ LIZARRALDE, Ramón. Literatura rumana. República de Las Letras, n. 87, 2004, p. 15-28.

SIMION, Eugen. Prefaţa. Eminescu - Opere vol. I-V. Bucarest: Editura Univers Enciclopedic, 1999-2000.

TOURY, Gideon. Descriptive Translation Studies and Beyond. Amsterdam y Filadelfia: Benjamins, 1995.

USCATESCU BARRÓN, Jorge. Centenario de Mihai Eminescu. Cuadernos Hispanoamericanos, n. 472, 1989, p. 79-85.

UȚĂ BURCEA, Ofelia. Contactos entre la literatura española y la literatura rumana en el ámbito de la traducción. Tesis doctoral. Madrid: Universidad Complutense, 2014.

Catalina Iliescu Gheorghiu estudió Filología Hispánica e Inglesa en la Universidad de Bucarest (Rumanía) y se Doctoró en estudios ingleses por la Universidad de Alicante (España) en 2002. Actualmente es profesora Titular del Departamento de Traducción e Interpretación y coordinadora de los Cursos de Verano de la Universidad de Alicante (España). Entre sus publicaciones destacan Introducción a la interpretación. La modalidad consecutiva $(2002,2005)$, Traducerea textului dramatic (2009), Traducción y (a)culturación en la era global (2012) y Un model polisitemic de analiză comparativă a textului dramatic din perspectiva traductologiei descriptive (2018). E-mail: iliescu@ua.es

Recebido em: 22/01/2018

Aceito em: 15/07/2018 